\title{
Undrained response of Sydney sand under non-reversal cyclic loading
}

\author{
Amirabbas Mohammadi ${ }^{1}$ and David Airey,** \\ ${ }^{1}$ The University of Sydney, School of Civil Engineering, Australia
}

\begin{abstract}
Stress history and loading path can significantly influence the cyclic response of sands. It is well known that cyclic behaviour under non-symmetrical cycling is generally different from that under symmetrical loading around zero deviator stress. Anisotropic consolidation prior to cycling in triaxial apparatus changes the behaviour by exerting an initial static shear stress on critical planes. The present paper reports the results from a number of cyclic triaxial tests on anisotropically consolidated samples of Sydney beach sand. The samples are reconstituted in the laboratory and subjected to non-reversal cycling in compression only loading under undrained conditions. Typical test behaviours are described and the effects of cyclic stress ratio and initial state on the response are discussed. It is shown that the state parameter is capable of predicting the cyclic resistance and the trend of excess pore water pressure generation during one-way compressional cycling and, as has been well established for simple loading paths, critical state soil mechanics is able to provide a reliable framework to characterize the behaviour under different cyclic loading conditions.
\end{abstract}

\section{Introduction}

Investigation of the cyclic behaviour of sands is of great interest because ground deformations during earthquakes can cause significant structural damage and lead to loss of life. Cyclic behaviour is commonly studied by conducting symmetrical cycling around zero deviator stress in triaxial apparatus. This loading condition, however, is far from reality in the majority of practical cases. For example, in sloping grounds or beneath a structure and its surrounding area, induced cyclic loading is generally non-symmetrical due to the existence of initial static shear stresses (also termed as sustained shear stresses) on the critical planes of soil elements.

To take into account the impact of this sustained shear stress on the cyclic response, triaxial tests should be carried out using anisotropic consolidation paths to impose a static shear stress on the planes of interest prior to cyclic loading. This procedure results in nonsymmetrical cycling that can involve either deviator stress reversal or non-reversal depending on the levels of static stress ratio and cyclic stress ratio applied, and provides a better approximation of the real conditions existing in most geotechnical engineering problems. Many researchers have attempted to characterize soils' responses under these types of loading path (e.g. [1-8]). However, while these works have contributed to gaining a basic understanding of the issue, the multiplicity of factors involved has led to many confusing and contradictory results, raising the need for further investigations. In the majority of published works, none or only one of the state variables (density or effective stress level) have been considered in the analysis in conjunction with the static stress ratio, and few efforts have been made to combine the effects of different state variables.

The state parameter $(\psi)$, introduced by Been and Jefferies [9], has proved to be an effective tool to combine the effects of density and stress level on the cyclic response of isotropically consolidated sands [10-12]. However, it may be problematic to rely on state parameter when it comes to anisotropic consolidation, because the initial shear stress, which is absent in isotropic conditions, may influence the behaviour on its own. In other words, the effectiveness of the state parameter in anisotropic conditions depends on whether or not it can normalise the effect of initial static shear stress. Yang and Sze $[5,6]$ have shown that state parameter works well for nonsymmetrical cycling, but this observation needs to be examined further for different soils and different loading conditions.

An extensive experimental program has been planned to address some of the gaps and unclear aspects of this topic, and conflicting results reported in the literature. This paper presents a number of preliminary results of tests planned to investigate whether the state parameter can be used to predict the cyclic strength and to characterize the process of excess pore water pressure generation during non-reversal cycling of Sydney sand. Comparisons will be made with previous results from sands subjected to symmetrical cyclic loading.

* Corresponding author: david.airey@sydney.edu.au 


\section{Materials and methods}

The material tested is Sydney beach sand. Figure 1 shows the grains size distribution of the soil. It is a poorly graded, uniform, clean sand classified as SP in the Unified System. The coefficients of uniformity and curvature are 1.5 and 1.1 , respectively.

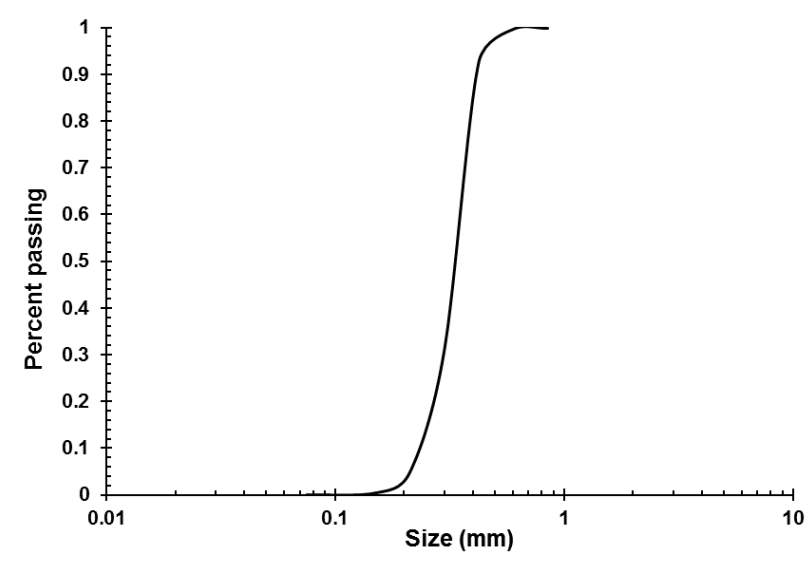

Fig. 1. Grain size distribution of Sydney sand.

A fully automated, computer controlled triaxial apparatus was used to perform the tests. All specimens were prepared using wet tamping, which involved pouring the soil in the mould in 12 equal layers and gently tamping each layer with a light tamper. The samples were of approximately $55 \mathrm{~mm}$ diameter and $110 \mathrm{~mm}$ height. After saturating the samples to ensure a B value of at least $95 \%$, anisotropic consolidation with the desired stress ratio was applied at a rate of about $5 \mathrm{kPa}$ per minute followed by a one hour creep stage. The samples were then subjected to cyclic loading with a frequency of around $0.01 \mathrm{~Hz}$ in undrained conditions.

\section{Testing program and typical results}

Table 1 summarizes the tests reported in this paper. $e$ and $p^{\prime}$ are the voids ratio and mean effective stress prior to cycling, respectively. Consolidation stress ratio $\left(K_{\mathrm{c}}\right)$ is the ratio of radial stress to axial stress during consolidation. Cyclic stress ratio (CSR) is defined as $q_{\text {cyc }} / 2 p$ where $q_{\text {cyc }}$ is the amplitude of the cyclic deviator stress during cycling. The state parameter $(\psi)$, as defined by Been and Jefferies [9], is the difference between the voids ratio prior to cycling and the voids ratio on the critical state line (CSL) at the current mean effective stress. The critical state line used to calculate the state parameter is shown in Figure 2. $N_{\mathrm{f}}$ is the number of cycles required for the axial strain to reach $5 \%$, which is considered here as the cyclic resistance of the soil.

Figure 3 presents a typical cyclic response obtained from test $\mathrm{T} 5$. It can be seen from Figure 3 a that axial strain continuously increases during cycling. The rate of strain increase was initially slow, but after $2500 \mathrm{~s}$ accelerated and the deformations kept on developing at a high and almost constant rate until cycling was stopped. Pore water pressure variations, however, show an opposite trend (Figure 3b). Following an initial rapid build-up associated with the first couple of cycles, the pore water pressure then increases at a high rate until a pore pressure ratio, $R_{\mathrm{u}}$ (Excess pore water pressure divided by mean effective stress) of around 0.65 is reached, after which the generation of pore water pressure decelerates rapidly. When the pore pressure ratio reaches about 0.75 , the pore water pressure remains more or less the same. This means that a state of zero effective stress $\left(R_{\mathrm{u}}=1\right)$ never happens and the soil does not liquefy.

Table 1. Details of tests conducted.

\begin{tabular}{|c|c|c|c|c|c|c|}
\hline $\begin{array}{c}\text { Test } \\
\text { Label }\end{array}$ & $\boldsymbol{e}$ & $\boldsymbol{p}^{\prime}$ & $\boldsymbol{k}_{\mathbf{c}}$ & $\mathbf{C S R}$ & $\boldsymbol{\psi}$ & $\boldsymbol{N}_{\mathbf{f}}$ \\
\hline $\mathrm{T} 1$ & 0.71 & 100 & 0.4 & 0.200 & -0.20 & 245 \\
\hline $\mathrm{T} 2$ & 0.71 & 100 & 0.4 & 0.250 & -0.20 & 25 \\
\hline T3 & 0.71 & 100 & 0.4 & 0.300 & -0.20 & 8 \\
\hline T4 & 0.73 & 300 & 0.7 & 0.175 & -0.14 & 13 \\
\hline T5 & 0.68 & 200 & 0.7 & 0.175 & -0.21 & 47 \\
\hline T6 & 0.67 & 300 & 0.7 & 0.175 & -0.20 & 40 \\
\hline T7 & 0.69 & 100 & 0.7 & 0.175 & -0.22 & 63 \\
\hline
\end{tabular}

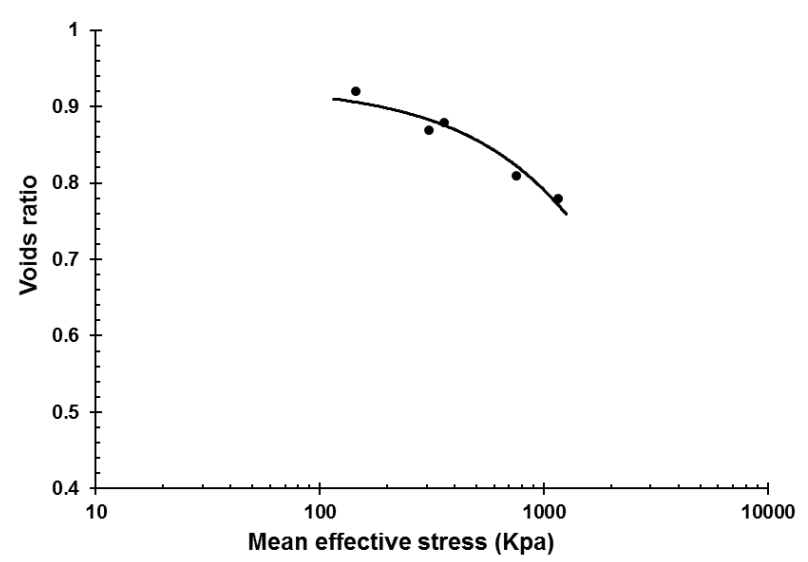

Fig. 2. Critical state line of Sydney sand (after Rahman \& Lo [13]).

Similar observations can also be made from Figures $3 \mathrm{c}$ and $3 \mathrm{~d}$. As cyclic loading is applied, plastic strain accumulates through a gradual trend without any flowtype behaviour (Figure 3c), and effective stress decreases until reaching a stable state where the effective stress path approaches the ultimate stress ratio (Figure 3d). A number of researchers have reported that limited flow can occur at some point during the plastic strain accumulation (e.g. [3, 7, 14]). This was not seen here, which can be attributed to the sample preparation method - due to its influence on soil's fabric - and also the non-reversal cycling applied.

This kind of behaviour in which the soil does not lose its stability and is stable when loading is stopped has been referred to in the literature with different terms such as cyclic mobility [4], plastic strain accumulation [5], and residual deformation [8].

\section{Effect of cyclic stress ratio}

The cyclic stress ratio determines the intensity of cyclic loading and is well known to have a significant effect on 

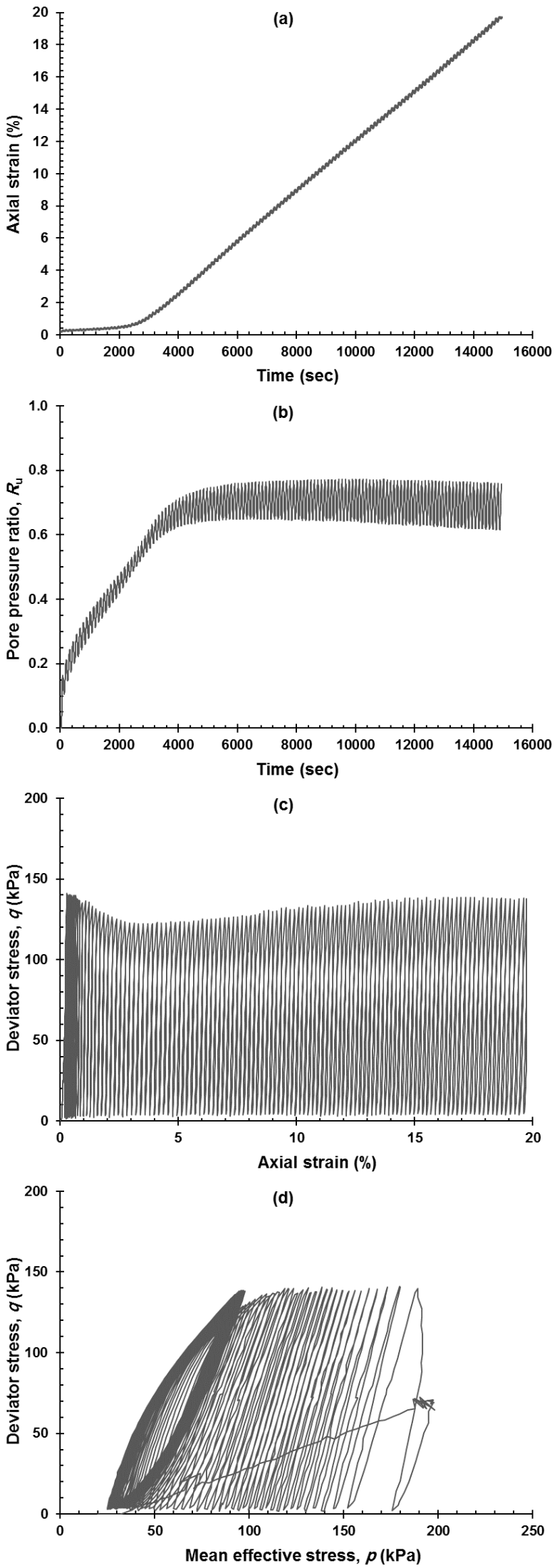

Fig. 3. Typical response (Test T5).

the cyclic response. Increasing cyclic stress ratio should normally reduce the cyclic resistance when other controlling factors are kept constant. As a result, examining its effect can be a good way of verifying the validity of test results. Figure 4 illustrates the variations of cyclic resistance with cyclic stress ratio. It is evident that, as expected, the samples fail at a smaller number of cycles as the cyclic stress ratio increases. An exponential relationship is derived which is similar to that reported for a different beach sand [15].

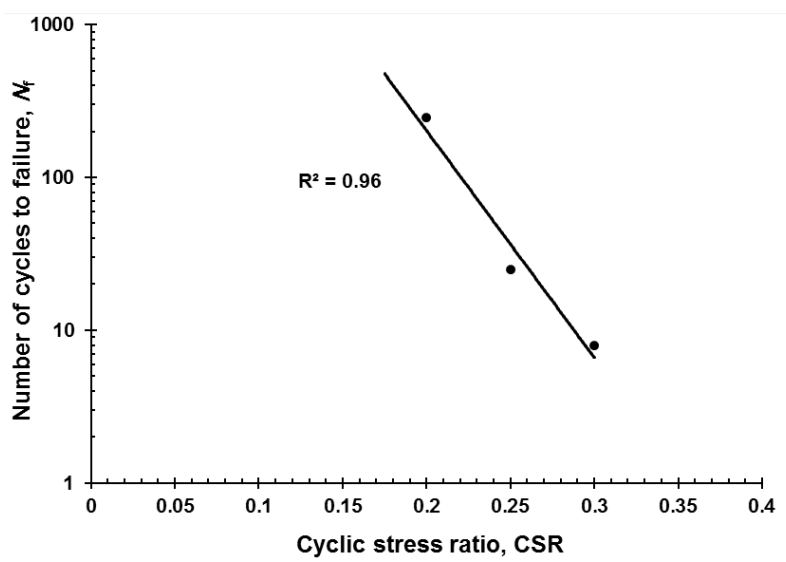

Fig. 4. Cyclic resistance against cyclic stress ratio $\left(k_{\mathrm{c}}=0.4\right.$, $\psi=-0.2)$.

Generation of excess pore water pressure can also be influenced by cyclic stress ratio. Plotted in Figure 5 are the normalised pore water pressures, normalized by the mean effective stress to eliminate the effect of consolidation stress, against time. It can be seen that greater pore water pressures are built up as the cyclic stress ratio increases. Decrease of pore water pressure after reaching its maximum value in test T3 is not usually seen in normally consolidated sands, but is a consequence of the high static stress. It should be noted that in these three tests, control over testing conditions including cyclic stress ratio, frequency and saturation has been imperfect. For example, there have been some fluctuations in the cyclic stress ratio applied in test $\mathrm{T} 2$ which is evident in its pore pressure curve. Although the observed trends may have been influenced by these errors, they can be considered accurate enough for the purpose of this section.

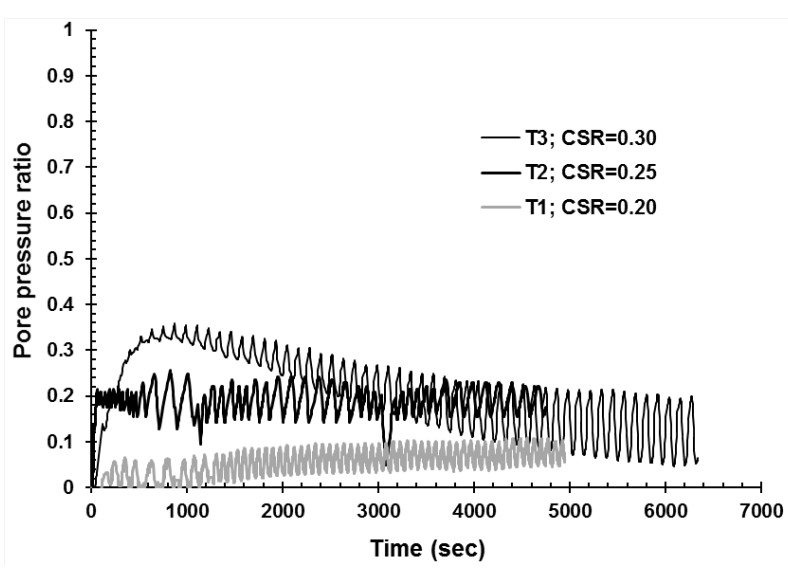

Fig. 5. Generation of excess pore water pressure for specimens with different cyclic stress ratios $\left(k_{\mathrm{c}}=0.4, \psi=-0.2\right)$. 


\section{Effect of initial state}

The initial state of a soil is determined by its voids ratio and mean effective stress prior to shearing. Combination of these two parameters locates the state of the soil in the space of $e-\ln p^{\prime}$. State parameter $(\psi)$, introduced by Been and Jefferies [9] as a state quantifier, has widely been used to describe the monotonic behaviour of sandy soils (e.g. [16-18]). Recently, different researchers have also characterized the cyclic response of isotropically consolidated sandy soils by means of the state parameter [10-12]. However, the use of state parameter to analyse the cyclic behaviour of sands with anisotropic consolidation has received little attention so far and remains to be addressed further.

Figures 6 and 7 show the changes in cyclic resistance with voids ratio and state parameter, respectively. As can be seen from the Figures, due to the impact of stress level the voids ratio alone is not able to predict the cyclic resistance, but the state parameter appears to do so effectively. This capability results from definition of the state parameter that captures both density and stress level at the same time and measures their combination relative to a reference state (CSL) which is unique for the soil. The correlation derived seems to be in a good agreement with the results reported by Yang and Sze $[5,6]$.

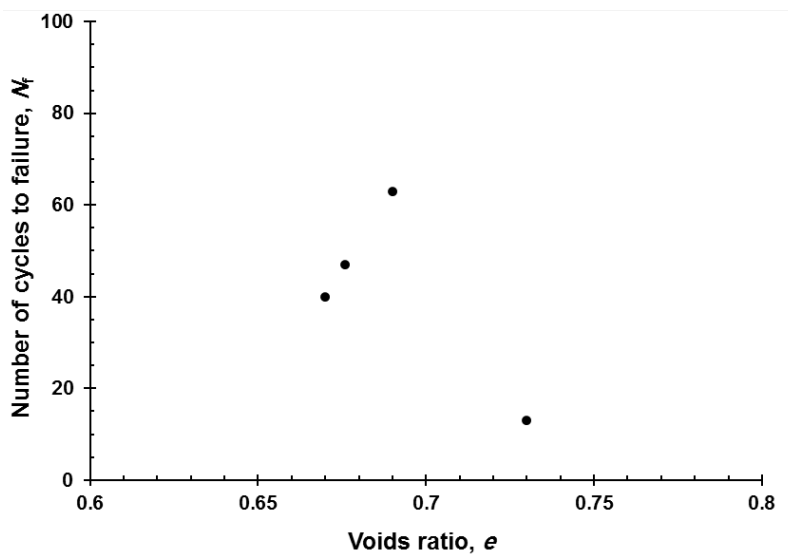

Fig. 6. Cyclic resistance against voids ratio $\left(k_{\mathrm{c}}=0.7\right.$, $\mathrm{CSR}=0.175$ ).

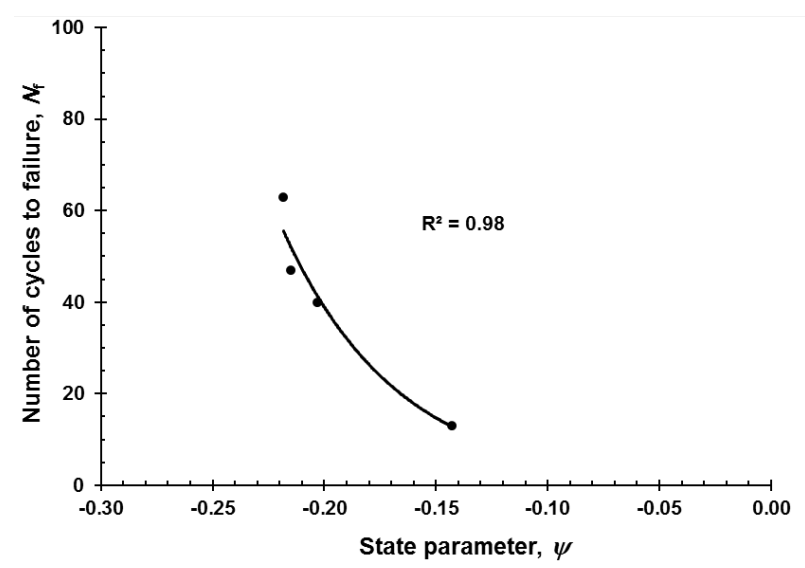

Fig. 7. Cyclic resistance against state parameter $\left(k_{\mathrm{c}}=0.7\right.$, $\mathrm{CSR}=0.175$ ).
In addition to the state parameter, stress ratio $\left(R_{\mathrm{s}}\right)$ and modified state parameter $\left(\psi_{\mathrm{m}}\right)$ have been proposed in the literature to quantify the state $[17,19] . R_{\mathrm{S}}$ is the ratio of current $p^{\prime}$ (prior to cycling) to $p^{\prime}$ on critical state line at current voids ratio. Modified state parameter is defined as $\psi_{\mathrm{m}}=\psi\left|1-1 / R_{\mathrm{s}}\right|$. The use of these indices has not been always successful and state parameter has proved to work generally better and more effectively [12]. Nevertheless, according to Figure 8, for the limited cyclic and consolidation stress ratios used in this work, $R_{\mathrm{s}}$ and $\psi_{\mathrm{m}}$ can be well correlated with the cyclic resistance.
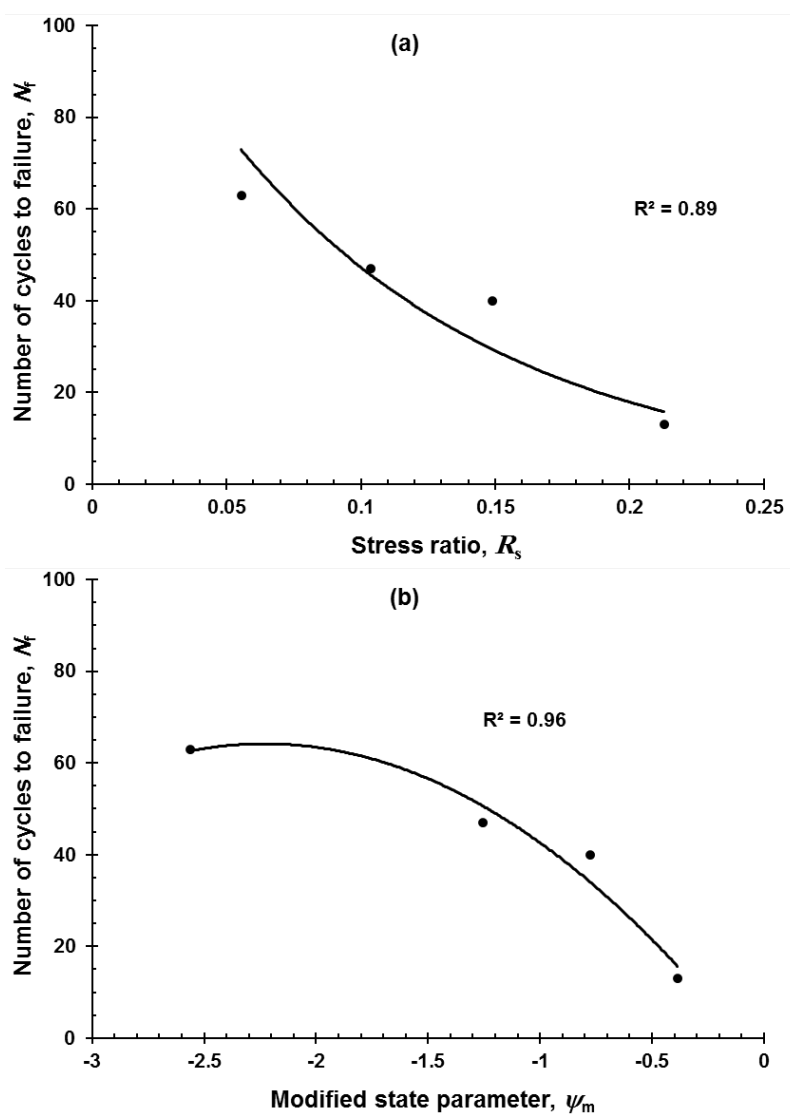

Fig. 8. Cyclic resistance against (a) stress ration, and (b) modified state parameter $\left(k_{\mathrm{c}}=0.7, \mathrm{CSR}=0.175\right)$.

The process of excess pore water pressure generation during cycling mirrors the cyclic behaviour and strength of granular material. Liquefiable sands, when sheared symmetrically (isotropic consolidation) or with sufficient stress reversal, normally experience progressive pore water pressure build-up up to a pore pressure ratio of around 1 which represents a state of zero effective stress and causes instability/liquefaction of the soil. In nonreversal cycling, however, generation of pore water pressure is capped at some level and $R_{\mathrm{u}}$ does not exceed a specific amount even at large deformations (Figure $3 b$ ).

Normalised excess pore water pressure curves from the tests with CSR $=0.175$ and different initial states are plotted in Figure 9. The data is presented up to an axial strain of about $20 \%$. It can be seen that all curves are capped by a pore pressure ratio of between 0.7 and 0.8 irrespective of initial state. It is expected that the value of 
the limiting $R_{\mathrm{u}}$ will be dependent on cyclic stress ratio and consolidation stress ratio. Figure 9 suggests that the position and trend of normalised excess pore water pressure curves do not appear to be a function of initial state of the soil, whereas for isotropically consolidated sands, they have been shown to be pronouncedly affected by the initial state (Figure 10) and well predicted by using the state parameter [15].

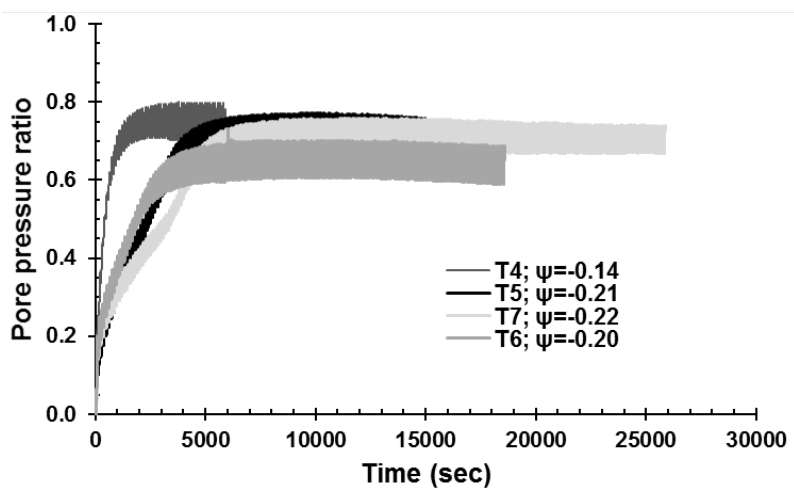

Fig. 9. Curves of pore pressure ratio for different initial states $\left(k_{\mathrm{c}}=0.7, \mathrm{CSR}=0.175\right)$.

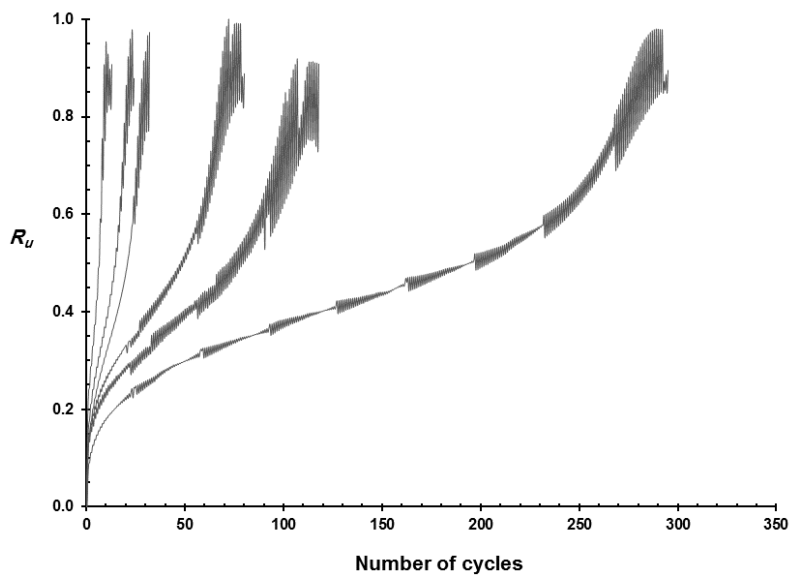

Fig. 10. Curves of pore pressure ratio for different initial states of an isotropically consolidated sand [15].

It has been demonstrated that in a semi-logarithmic space, normalised excess pore water pressure curves of isotropically consolidated beach sand can be described by a bi-linear trend and characterized in terms of state parameter [15]. Figures 11 to 13 indicate that a similar approach also works for simplifying the behaviour under non-reversal cycling. Figure 11 shows linear pore pressure data on a semi-logarithmic scale. The gradients of the trend lines are plotted versus state parameter in Figure 12 which reveals a reasonable correlation.

In order to fully characterize the simplified process of excess pore water pressure generation, one point from the fitted trend lines has been correlated with the state parameter, as shown in Figure 13, for the pore pressure ratio at $10^{\text {th }}$ cycle of loading against state parameter. Although a tentative line has been drawn through the data, clearly a wider range of tests are required to have confidence in the indicated trend.
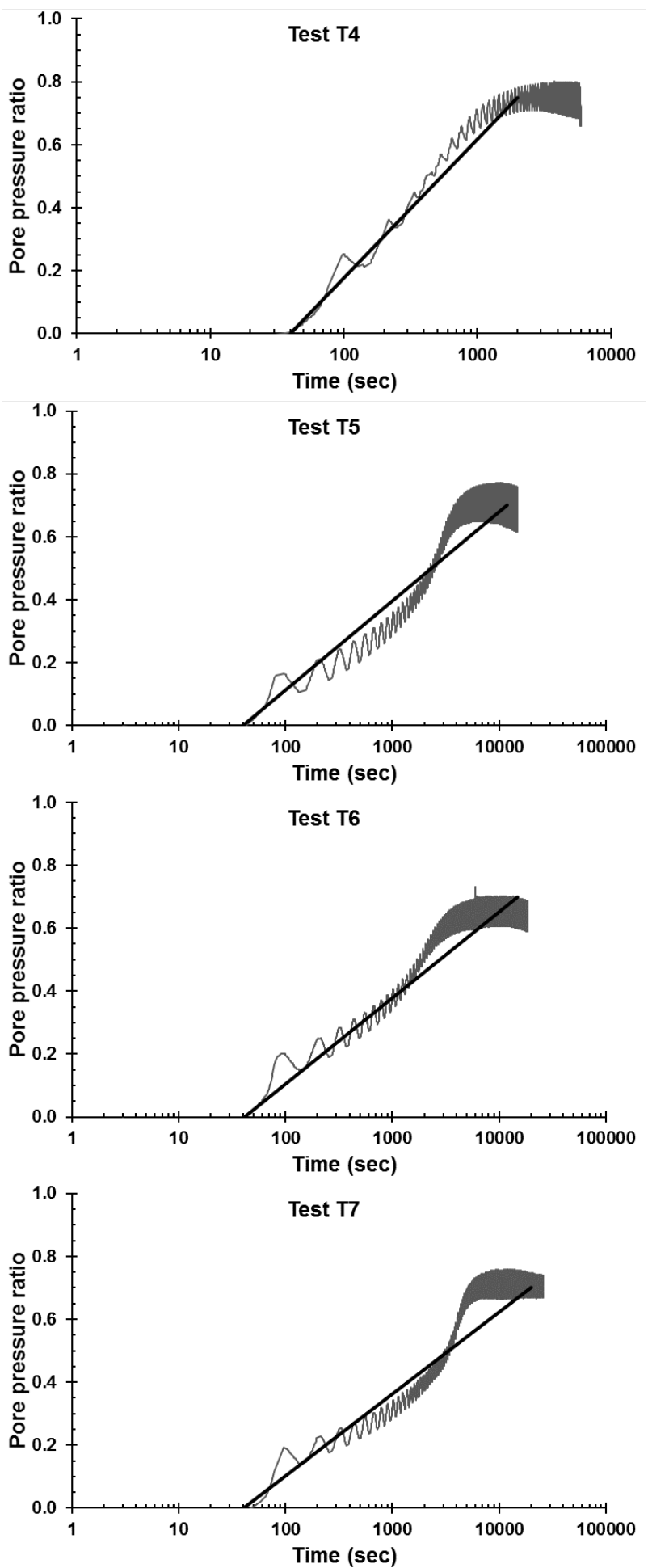

Fig. 11. Curves of pore pressure ratio for different initial states on semi-logarithmic scale $\left(k_{\mathrm{c}}=0.7, \mathrm{CSR}=0.175\right)$.

\section{Conclusions}

The undrained triaxial tests on Sydney sand described in this paper demonstrate how cyclic stress ratio and initial state affect the cyclic response of an anisotropically consolidated beach sand. It was shown that the excess pore water pressure generation during non-reversal cycling can be simplified by a linear trend in semi- 
logarithmic space, similarly to symmetrical cycling. The state parameter $(\psi)$ manifested strong correlations with cyclic strength and the trend of pore pressure ratio, as observed before for isotropically consolidated soils. Other state quantifiers, namely stress ratio and modified state parameter worked favourably as well.

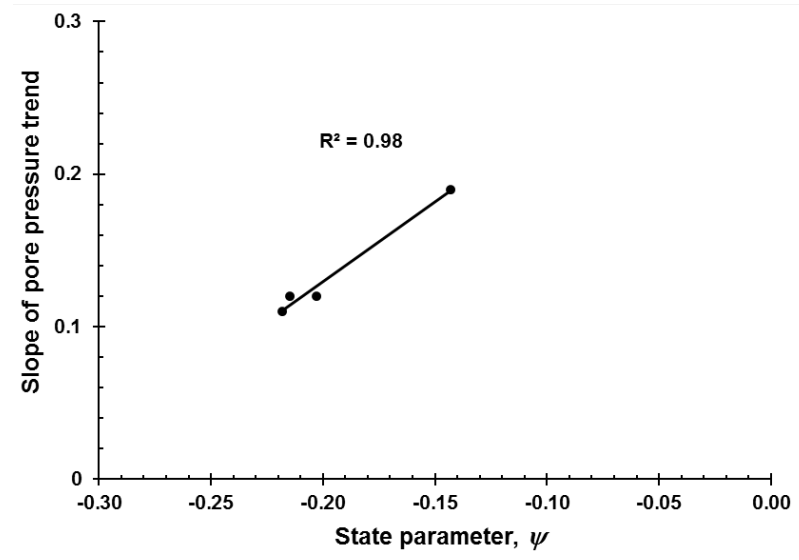

Fig. 12. Slope of simplified pore pressure trend against state parameter $\left(k_{\mathrm{c}}=0.7, \mathrm{CSR}=0.175\right)$.

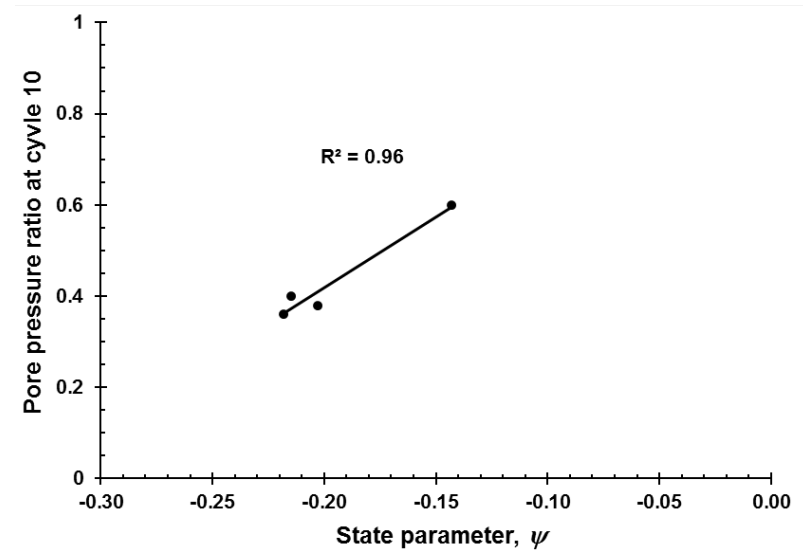

Fig. 13. Pore pressure ratio at $10^{\text {th }}$ cycle against state parameter $\left(k_{\mathrm{c}}=0.7, \mathrm{CSR}=0.175\right)$.

\section{References}

1. K.L. Lee, H.B. Seed, J. Soil Mech. Found. Div. ASCE (1967)

2. Y.P. Vaid, J.C. Chern, Soils found. 23(1), 47-60 (1983)

3. M. Hyodo, H. Tanimizu, N. Yasufuku, H. Murata, Soils found. 34(1), 19-32 (1994)

4. V.N. Ghionna, D. Porcino, J. Geotech. Geoenviron. Eng. ASCE 132(2), 194-202 (2006)

5. J. Yang, H.Y. Sze, Géotechnique 61(1), 59-73 (2011a)

6. J. Yang, H.Y. Sze, J. Geotech. Geoenviron. Eng. ASCE 137(12), 1275-1285 (2011b)

7. H.Y. Sze, J. Yang, J. Geotech. Geoenviron. Eng. ASCE 140(1), 152-169 (2014)

8. Z.X. Yang, K. Pan, Soil Dyn. Earthq. Eng. 92, 68-78 (2017)
9. K. Been, M.G. Jefferies, Géotechnique 35(2), 99-112 (1985)

10. C.A. Stamatopoulos, Soil Dyn. Earthq. Eng. 30(8), 662-678 (2010)

11. A.B. Huang, S.Y. Chuang, Soils found. 51(6), 991 $1001(2011)$

12. A. Qadimi, A. Mohammadi, Soil Dyn. Earthq. Eng. 66, 443-458 (2014)

13. M.M. Rahman, S.R. Lo, 16th Southeast Asian Geotechnical Conference (2007)

14. S. Sivathayalan, D. Ha, Can. Geotech. J. 48(10), 1471-1484 (2011)

15. A. Mohammadi, A. Qadimi, Soil Dyn. Earthq. Eng. 77, 152-163 (2015)

16. C.W. Ng, W.T. Fung, C.Y. Cheuk, L. Zhang, J. Geotech. Geoenviron. Eng. ASCE 130(1), 36-44 (2004)

17. D.C. Bobei, S.R. Lo, D. Wanatowski, C.T. Gnanendran, M.M. Rahman, Can. Geotech. J. 46(3), 281-295 (2009)

18. M.M. Rahman, S.R. Lo, M.A.L. Baki, Acta Geotech. 6(4), 183-194 (2011)

19. E.U. Klotz, M.R. Coop, Géotechnique 52(8), 620621 (2002) 